\title{
Pack Palsy
}

\author{
Maj G J Attard, \\ MD, FRCS(Ed), RAMC \\ *Queen Elizabeth Military Hospital, Woolwich
}

SUMMARY: A case of 'Pack Palsy' in a previously fit soldier caused by incorrect adjustment of the strapping of his pack is described. The resulting disability was severe and recovery, although complete, was prolonged. Realization of the potential for brachial plexus injury, particularly in the combat situation, when the duration of march and the rough terrain cannot be varied is strongly emphasised. The mechanies as well as the two different sites of injury are described.

\section{Case Report}

The patient, a previously fit $\mathbf{3 2}$ year old corporal, had been well used to prolonged runs over rough ground with a loaded Bergen for several years. He had started on an intensive programme of fitness training five months earlier with a view to transfer to the SAS. His schedule involved a minimum ten mile run with a 50lb loaded Bergen, several times a week. On the preceding weekend he had lent his Bergen to one of his mates who was of a different build, but then forgot to readjust the straps.

At the end of the run he developed a cramp-like feeling and both his forearms and hands felt paralysed and numb and he was unable to remove his pack unaided. He felt no actual pain but described both his forearms as feeling very tense. This was more marked on the right side. Both arms and hands appeared blotchy and his hands assumed a claw-like position. He lost all motor power and sensation in his hands and wrists for about 24 hours. Following this, motor power and sensation slowly improved but he was unable to carry out fine movements with his hands. He also complained that both his hands felt unusually cold and he was compelled to wear gloves.

He presented at surgical out-patients five days after injury. On examination both his hands and forearms appeared blotchy and there was very marked muscle and sensory impairment largely in the $\mathrm{C} 8 \mathrm{Tl}$ distribution. Both radial pulses were normal. Routine X-rays of his cervical spine and thoracic inlet were normal.

The patient was treated with physiotherapy and there was a gradual return of normal motor and sensory function over an eight week period. By the fourteenth week he was back to running with a loaded Bergen, without any further problems.

\section{Discussion}

A rucksack is a device for carrying loads in which the weight is transmitted to straps, which come over the shoulder and underneath the axilla with no means of firmly attaching the pack to the carrier. It is meant for carrying loads less than 11.4 kilos.

\footnotetext{
*Now Birmingham General Hospital (Surgery)
}

A backpack by virtue is designed to remove some of the weight-bearing load from the shoulder girdle and distribute it to the hips and back. It thus enables the individual to carry much heavier loads with a minimum of discomfort.

Incorrect adjustment of strapping will cause compression of the nerves of the brachial plexus as they emerge from the axillary fossa on the medial side of the arm, just beyond the protection of the pectoralis major This will result in the type of injury described.

A different injury can also result from compression of the upper trunk of the brachial plexus by the clavicle against the rib cage. This can occur with a properly placed pack. The precipitating factors here are obviously the weight of the load, the duration for whic it is carried and the terrain patrolled. Climbing over hill or rocky ground, especially when a need to balance an $\$$ hold on is required, increases the likelihood of injuryo Other compromising factors are previous clavicle or rif injuries, vascular anomalies, anomalous muscle insertion, fibrous bands, underdeveloped musculature and sloping shoulders ${ }^{2-5}$. Daube, reporting on 17 cases seen involving the "airborne rucksack" in Vietnam, only found an underlying abnormality in two cases ${ }^{3}$.

The clinical picture is similar to an Erb's paralysis. There is weakness chiefly in muscles supplied by the suprascapular and axillary nerves and a sensory impairment predominantly in a $\mathrm{C5}$ and $\mathrm{C} 6$ distribution. There is significant impairment of the radial and musculocutaneous nerves. The median nerve is only minimally involved while the ulnar nerve is quite often spared.

There is a predilection for the nondominant side to be affected first, although bilateral involvement may occur. The cause of this could be a relative weakness on the nondominant side or is indeed more likely postural. As the practice is to hold the rifle in the right hand and to use the left for balance and pushing and pulling, this results in more stress being applied to the left shoulder.

\section{Conclusion}

Although the prognosis for eventual recovery is good it is extremely important that military personnel realize 
the serious potential for brachial plexus injury in the field.

Proper instruction and training with a pack for a period of time should be carried out before wearing it under demanding conditions. All concerned should be made aware of the maximum weight that can safely be carried for long periods, particularly when patrolling over rough ground, and the consequences of exceeding this weight, as well as the hazards of faulty strapping.

\section{REFERENCES}

1. BoM, F. A case of "Pack Palsy" from the Korean War. Acta psychiat Neurol Scand 1953; $28: 1-4$.

2. Goodson, J D. Bracial Plexus injury from tight backpack straps. New England J Med $1981 ; 305(9)$.

3. DAUBE, J R. Rucksack paralysis. JAMA 1969; 2082447.

4. Woodhall, B. Pack Palsy. Bull Us Army Med Dept 1944; 2: 112-117.

5. Payne, E E. Pall-Bearers Palsy. Brit Med J 1966; 2: 808-809.

\section{A LIGHTER LOOK AT YELLOWLEES}

(From the Secretariat)

They said there's a study, of good men and true, Of medics of brown, and of dark and light blue, But who to conduct it, this latest review?

Why! Sir Henry, with Martyn and me.

We studied the writing of earlier teams

To see what they thought of the medical schemes, Was there a pointer or two 'mongst the reams?

For Sir Henry, and Martyn and me.

They all seemed to feel that a closeness was due, A closeness of purpose and management too. But was there perhaps an alternative view?

For Sir Henry, and Martyn and me.

We visited many who might shed some light, Both home and abroad or wherever seemed right. Could there be some to bring aid to the plight?

Of Sir Henry, and Martyn and me.

Our hosts and hostesses all over the earth Provided occasions for food, wine and mirth.

But sadly this fare did add to the girth Of Sir Henry, and Martyn and me!

We learnt of the roles in both peace and war, Of navies and armies and planes by the score.
Of much that was new; but much heard before By Sir Henry, and Martyn and me.

We learnt of the medical plans in support In case there should ever be wars to be fought. And views from both seniors and juniors we sought Did Sir Henry, and Martyn and me.

And all this confirmed views already made plain, That medics of brown and of blues must remain.

A fact to be stated with all might and main By Sir Henry, and Martyn and me.

But management! That was a different game, With three separate staffs doing jobs all the same, Or that's how it seemed, in all but the name, To Sir Henry, and Martyn and me.

And so all three Services, on the same side, With joint staffs could manage, and manage with pride Their assets together, were they unified By Sir Henry, and Martyn and me.

So thus did the recommendation appear To Ministers who were willing to hear A sensible plan for the future made clear By Sir Henry, and Martyn and me. 